\title{
Ants' Acquisition of A Symbol for Zero and Its Use to Add
}

\author{
Marie-Claire Cammaerts ${ }^{1} \&$ Roger Cammaerts ${ }^{1}$ \\ ${ }^{1}$ Independent researcher, retired from the Biology of Organisms Department, University of Brussels, Belgium. \\ ${ }^{2}$ Independent researcher, retired from the Natural and Agricultural Environmental Studies Department (DEMNA) \\ of the Walloon Region, Belgium. \\ Correspondence: Marie-Claire Cammaerts, independent researcher, 27, Square du Castel Fleuri, 1170 Bruxelles, \\ Belgium, tel: 32267349 69; Email addresses: mccammaerts@gmail.com
}

Received: September 5, 2019

Accepted: October 1, 2020

Online Published: December 2, 2020

doi:10.5539/ijb.v12n4p1

URL: doi: $10.5539 / \mathrm{ijb} . v 12 \mathrm{n} 4 \mathrm{p} 1$

\begin{abstract}
It has been previously shown that workers of the ant Myrmica sabuleti can add up numbers of elements when seeing the result of the operation during training, can acquire multiple numerical symbolisms and can make additions using learned numeric symbols. They have also been shown to acquire the notion of zero through experiences. Here, we examined if these ants can associate a symbol with zero and can use this symbol to add. Working on four colonies, we found that the ants acquired a numerical symbolism for zero, and that they used this acquisition for making the additions $1+0,2+0,3+0,4+0$. This ability simply resulted from operative conditioning and from the ants' capability in adding up two amounts sighted side by side. The latter imperative condition shows that ants' numerical cognitive faculties are at a lower level than that observed in honeybees, in some birds and monkeys.
\end{abstract}

Keywords: Adding up numbers, Myrmica sabuleti, numerosity abilities, operative conditioning

\section{Introduction}

The ability to assess relative quantities of elements (quantity discrimination) has been observed, among others, in fishes (Agrillo, Dadda, Serena, \& Bisazza, 2009; Stancher, Sovrano, Potrich, \& Vallortigara, 2013; Agrillo, Miletto Petrazzini, \& Bisazza, 2017), frogs (Stancher, Rugani, Regolin, \& Villortigara, 2015; Rose, 2018), salamanders (Uller, Jaeger, Guidry, \& Martin, 2003; Krusche, Uller, \& Dicke, 2010;), birds (Garland, Low, \& Burns, 2012; Tornick, Callahan, \& Gibson, 2015; Rugani, Villortigara, \& Regolin, 2014; Hunt, Low \& Burns, 2008; Pepperberg \& Gordon, 2005; Ditz \& Nieder, 2016), rats (Cox \& Montrose, 2016), canids (Baker, Morath, Rodzon, \& Jordan, 2012; Range, Jenikejew, Schröder, \& Virányi, 2014), elephants (Perdue, Talbot, Stone, \& Beran, 2012; Irie, Hiraiwa-Hasegawa, \& Kutsukake, 2019); monkeys (Addessi, Crescimbene, \& Visalberghi, 2008; Beran, 2008) and adult apes (Woodruff \& Premack, 1981; Hauser, Carey, \& Hauser, 2000; Tomonaga, 2008), but also in spiders (Rodriguez, Briceno, Briceno-Aguilar, \& Höbel, 2015; Cross \& Jackson, 2017) and in the mealworm beetle (Carazo, Fernandez-Perea, \& Font, 2012).

Precise counting (i.e. a one-to-one correspondence: Matsuzawa, 2009) is a prerequisite to the ability of adding up or subtracting numbers of elements. The ability to make small arithmetic operations was proved to be detained by some birds (Brannon, Wusthoff, Gallistel, \& Gibbon, 2001; Garland \& Low, 2014; Rugani, Fontanari, Simoni, Regolin, \& Villortigara, 2009), monkeys (Hauser, MacNeilage, \& Ware, 1996; Sulkowski \& Hauser, 2001; Uller, Hauser, \& Carey, 2001; Brannon \& Terrace, 2000; Flombaum, Junge, \& Hauser, 2005), and chimpanzees (Rumbauch, Savage-Rumbauch, \& Hegel, 1987).

Numerical symbolism consists in associating each number with a corresponding symbol, and this has been shown to be achieved by pigeons, a parrot, primates as well as bees. Pigeons (Columba livia) could associate visual symbols with up to 4 elements (Xia, Siemann \& Delius, 2000). A grey parrot (Psittacus erithacus) could be learned to associate vocal and visual symbols with at least 6 elements (Pepperberg, 2006a, b). Arabic numerals 0 to 9 could also be associated with their corresponding number of food items by rhesus monkeys (Macaca mulatta: Washburn \& Rumbauch, 1991), squirrel monkeys (Saimiri sciureus: Olthof, Iden, \& Roberts, 1997), as well as by capuchin (Cebus apella) and rhesus monkeys (Beran, Harris, Evans, Klein, Chan, Flemming, \& Washburn, 2008). Moreover, the latter species could also perform the task above chance level in presence of a novel situation (Beran, et al., 2008). Chimpanzees (Pan troglodytes) can be learned to associate Arabic numbers with 1 to 7 or 9 elements 
(Murofushi, 1997; Matsuzawa, 1985; Beran, 2004) including the symbol 0 for "nothing" (Biro \& Matsuzawa, 2001). Honeybees (Apis mellifera) could be learned to associate symbols such as shapes with a given number of elements ( 2 or 3 dots) and elements with shapes, but could not reverse the task if only experienced in one direction (Howard, Avarguès-Weber, Garcia, Greentree, \& Dyer, 2019b).

Adding up or subtracting amounts using symbols has been obtained in pigeons by Xia et al. (2000). A grey parrot could also make additions using learned symbols (Pepperberg, 2006a). As for primates, chimpanzees could make additions using Arabic numbers 0 to 4 (Boysen \& Berntson, 1989). Being rewarded when giving a correct response through classical conditioning, honeybees learned to add up 1 to 1,2 or 4 elements when the elements were blue, or to subtract 1 from 2, 4 or 5 elements when the elements were yellow, the number 3 being used as a novelty for testing the learned arithmetic ability of the bees (Howard, Avarguès-Weber, Garcia, Greentree \& Dyer, 2019a). They are thus able to use symbols (colors) as arithmetic operators for adding or subtracting one element from 1 to 4 elements (shapes, whatever their appearance) (Howard, Avarguès-Weber, Garcia, Greentree, \& Dyer, 2019c).

Understanding the notion of 'zero' is not an ability commonly presented by animals, even by humans. The understanding of numbers and of the notion of zero by a grey parrot individual named 'Alex' was studied in several steps. A first training learned it to report vocally 'none' to the absence of difference between two objects (Pepperberg, 1988). After having learned to associate symbols (vocal English labels) to numerosities 1 to 6 (Pepperberg, 1994), the same parrot could, without training, count 1 to 6 items and used "none" for the absence of any quantity, approaching so the notion of zero (Pepperberg \& Gordon, 2005). Thereafter, Alex could make additions, from 'zero' to 6, understanding number symbols as abstract representations, although his use of 'none' did not denote a specific numerosity (Pepperberg, 2006a, b; 2012). A chimpanzee, 'Ai', previously trained in the use of Arabic numerals 1 to 9 could master the correspondence between the numeral zero and the absence of an item as well as correctly ordering the zero in an ascending series of symbols, but confusion between 0 and 1 remained a frequent error (Biro \& Matsuzawa, 2001). Honeybees succeeded in discriminating 1 to 6 numbers of elements, then in discriminating these numerosities from an empty set: they thus have the notion of 'what is less than' and 'what is greater than' and perceive an empty set as an element located at the lower end of a continuous sequence of numbers (Howard, Avarguès-Weber, Garcia, Greentree, \& Dyer, 2018). Nieder (2016) explored human history and humans' neurophysiology, and proposed that the emergence of the notion of zero goes through four stages before being fully, abstractly thought: 'nothing' perceptible to the senses; categorical, different from something; quantitatively empty; and finally as a true number with its corresponding symbol (i.e. an abstract notion of zero).

It has been shown that workers of the ant Myrmica sabuleti Meinert, 1861 have the notion of zero, can add up numbers of elements when seeing the results of the operation during training, can acquire single as well as multiple symbolisms, and can add up learned symbols (Cammaerts \& Cammaerts, 2019a, b, 2020c, d, e). Going further in this quest about the ants' numerical abilities, we wondered if they could acquire a symbolism for zero and use it for making additions including a zero. The present paper deals with such an investigation.

\section{Material and Methods}

\subsection{Collection and Maintenance of Ants}

The experiments were performed on four colonies of M. sabuleti collected in September 2019 in an abandoned quarry located at Olloy/Viroin (Ardenne, Belgium). These colonies contained about 500 workers, a queen and brood. They nested under stones and grass. Each colony (labeled A, B, C or D) was maintained in the laboratory in one to two glass tubes half filled with water, a cotton plug separating the ants from the water. The nest tubes of each colony were deposited in a tray $(30 \mathrm{~cm} \times 15 \mathrm{~cm} \times 5 \mathrm{~cm})$ which served as a foraging area and the borders of which were slightly covered with talc to prevent escaping. On this area, pieces of Tenebrio molitor larvae (Linnaeus, 1758) were deposited three times per week on a glass piece, and sugar water was permanently provided in cotton plugged tubes. The ambient laboratory temperature was $c a 20^{\circ} \mathrm{C}$, the humidity $c a 80 \%$, the lighting 330 lux while working on ants, and the electromagnetism $2 \mu \mathrm{Wm}^{2}$.

\subsection{Experimental Design}

This design is schematized in Figure 1. The ants were trained in their foraging area. During a first training session, the cues the ants were expected to memorize were located near their food, and the ones they should not memorize were located far from any reward, i.e. behind the nest tubes. During a second training session, the cues the ants were expected to add up were located at the nest entrance. The ants were tested in a separate tray $(21 \mathrm{~cm} \mathrm{x} 15 \mathrm{~cm} \times$ $7 \mathrm{~cm}$ ), the borders of which having been slightly covered with talc. After the first training session, they were tested in front of two different cues set at about $8 \mathrm{~cm}$ from one another. After the second training session, the ants were tested in front of three different cues set at about $6 \mathrm{~cm}$ from one another. 


\subsection{Cues presented to the ants}

The cues presented to the ants during their first and second training and testing sessions are schematized in Figure 1. The cues were a number of black circles (diameter $=0.5 \mathrm{~cm}$ ) or a symbol corresponding to a number of such circles. Each one was drawn inside a square $(2 \mathrm{~cm} \times 2 \mathrm{~cm})$ using Word ${ }^{\circledR}$ software. Each of these squares was printed, cut, and tied on the vertical front face of a stand $(2 \mathrm{~cm} \times 2 \mathrm{~cm})$ made of strong white paper (Steinbach $\mathbb{}()$ and maintained vertically thanks to a horizontal part $[2 \times(1 \mathrm{~cm} \mathrm{x} 0.5 \mathrm{~cm})]$ duly folded (left photo at the bottom of Figure 1). The cues provided to each four colonies, during their first and second training sessions, as well as during their first and second testing sessions were the following ones.

During the first training session, the ants of colonies A, B, C, and D were provided with a stand bearing 1,2,3 or 4 black circles respectively as well as with a stand bearing a symbol corresponding to these 1,2,3 or 4 circles, these stands being set aside the sugar water tube, the stand with a number of circles on one side of the tube, and the stand with the symbol on the other side. Each colony was also provided with a stand bearing a blank paper $(2 \mathrm{~cm} \times 2 \mathrm{~cm})$ and a stand bearing a symbol for zero (one of these two stands was situated on the left, the other on the right of the meat food), and with two stands each bearing 5 circles set behind the nest, far from any reward.

The day after, the ants were tested daily, successively in front of the number of circles set near the sugar water tube versus 5 circles, of the symbol set near the sugar water tube versus 5 circles, of the number of circles versus the corresponding symbol set near the sugar water tube, then again successively in front of a blank paper versus 5 circles, of the symbol for zero versus 5 circles, and in front of a blank paper versus the symbol for zero. These six tests made over six days allowed checking if the ants duly associated the presented number of circles and the blank paper (i.e. zero, no circle) with their corresponding symbols.

During their following second training session, the ants of colonies A, B, C, and D were provided with a stand bearing 1,2,3 or 4 black circles respectively and with a stand bearing a blank paper, these two stands being set side by side on the left of the nest entrance. They were also provided with a stand bearing a symbol for 1, 2, 3 and 4 respectively and with a stand bearing the symbol for zero, these two stands being set side by side on the right of the nest entrance.

During the two following days, the ants of colonies A, B, C, and D were first tested in front of a stand bearing 5 circles versus respectively, a stand bearing 1,2,3 or 4 black circles versus a stand bearing a blank paper, and thereafter in front of a stand bearing 5 circles versus a stand bearing respectively the symbol for 1,2,3 or 4 versus a stand bearing the symbol for zero. These two tests made over two days allowed examining if the ants could make the proposed additions $(1+0 ; 2+0 ; 3+0$; and $4+0)$ using not only the numbers of elements but also their symbols.

\subsection{Experimental Protocol}

During their first and second training sessions, the ants present in the vicinity of the six presented cues were counted 32 times over the 6 experimental days ( 6 times over 4 days and 4 times over 2 days) (Training I) and 8 times over the 2 experimental days ( 4 times over 2 days) (Training II). The mean of these 32 or 8 counts was established and is given for each experiment in the text only. This information was recorded to check if the trained ants were sufficiently numerous near the cues for seeing them and making the required associations or additions. These counts required no statistical analysis.

For making a test, 25 foragers were transferred into their own tray devoted to testing, in front of the two or three cues required for the test. The 25 ants freely moved in the tray, perceived the cues and moved towards them, staying 2 to 20 seconds near those of their choice. Of course, the same ants could go to the two or three presented cues or elsewhere. The numbers of ants sighted at a distance less than $2 \mathrm{~cm}$ of each kind of cue were punctually counted 20 times (every 30 seconds) over 10 experimental minutes. The 20 counts of ants sighted near each cue also allowed calculating the proportion of ants' responses to each cue. In the tray devoted to testing, the 'correct' cue was randomly set on the left or on the right. After each test, the ants were put back into their foraging area, near their nest entrance. The twenty numbers chronologically obtained for each cue were summed by four to obtain five groups of numbers. The five pairs of groups of numbers obtained for two cues (the two presented cues or two of the three presented cues) were compared to one another using the non-parametric matched-pairs signed-ranks test of Wilcoxon. The critical P value was read in Siegel \& Castellan (1988) Table H for small sample sizes. A one-tailed test was used when the comparisons resulted from a conditioning. A two-tailed test was used when the comparison involved 1- 4 circles and their symbols, the ants having been conditioned to each of these kinds of cues. 

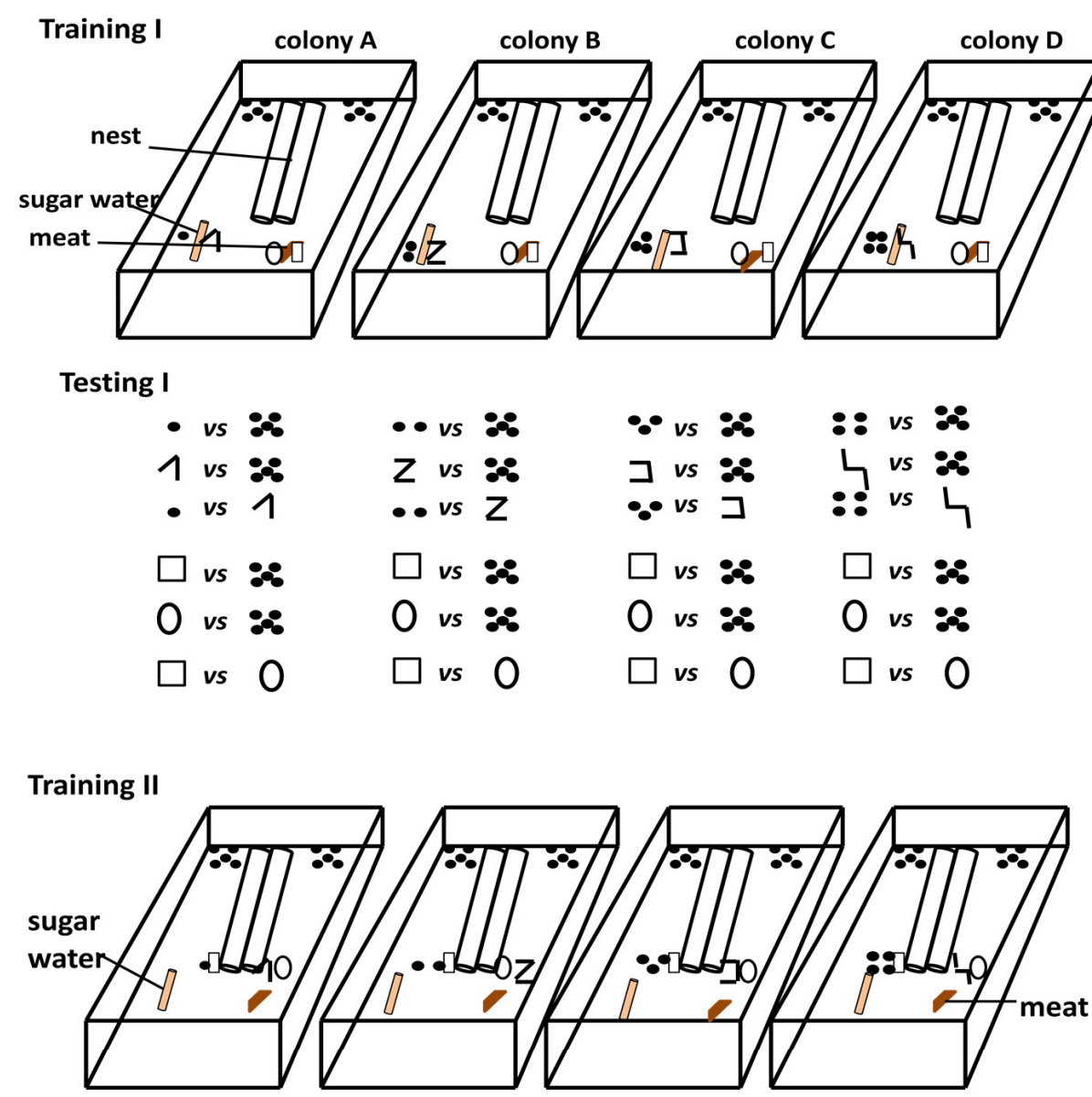

Testing II
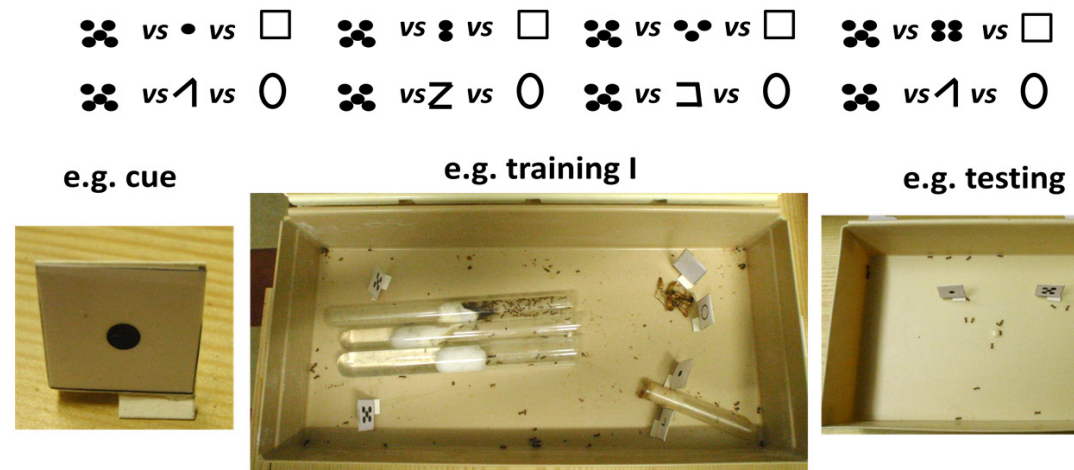

e.g. testing I

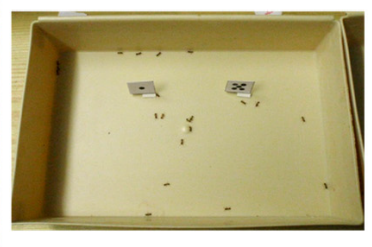

Figure 1. Schema of the experimental design and protocol used to examine if ants could learn and use a symbol for zero

The ants were trained to associate a symbol with a number of black circles, and a symbol with zero circle versus a stand bearing 5 circles and located far from any reward (Training I). The ants were then tested for checking their acquisition of these two associations (Testing I). Thereafter they were trained for adding up a number of black circles and zero circle, as well as the two symbols previously memorized (Training II). Finally, they were tested for checking if they could make the two proposed additions (Testing II). Illustrations are given in Figure 2, numerical results in Table 1, and details in the text. 


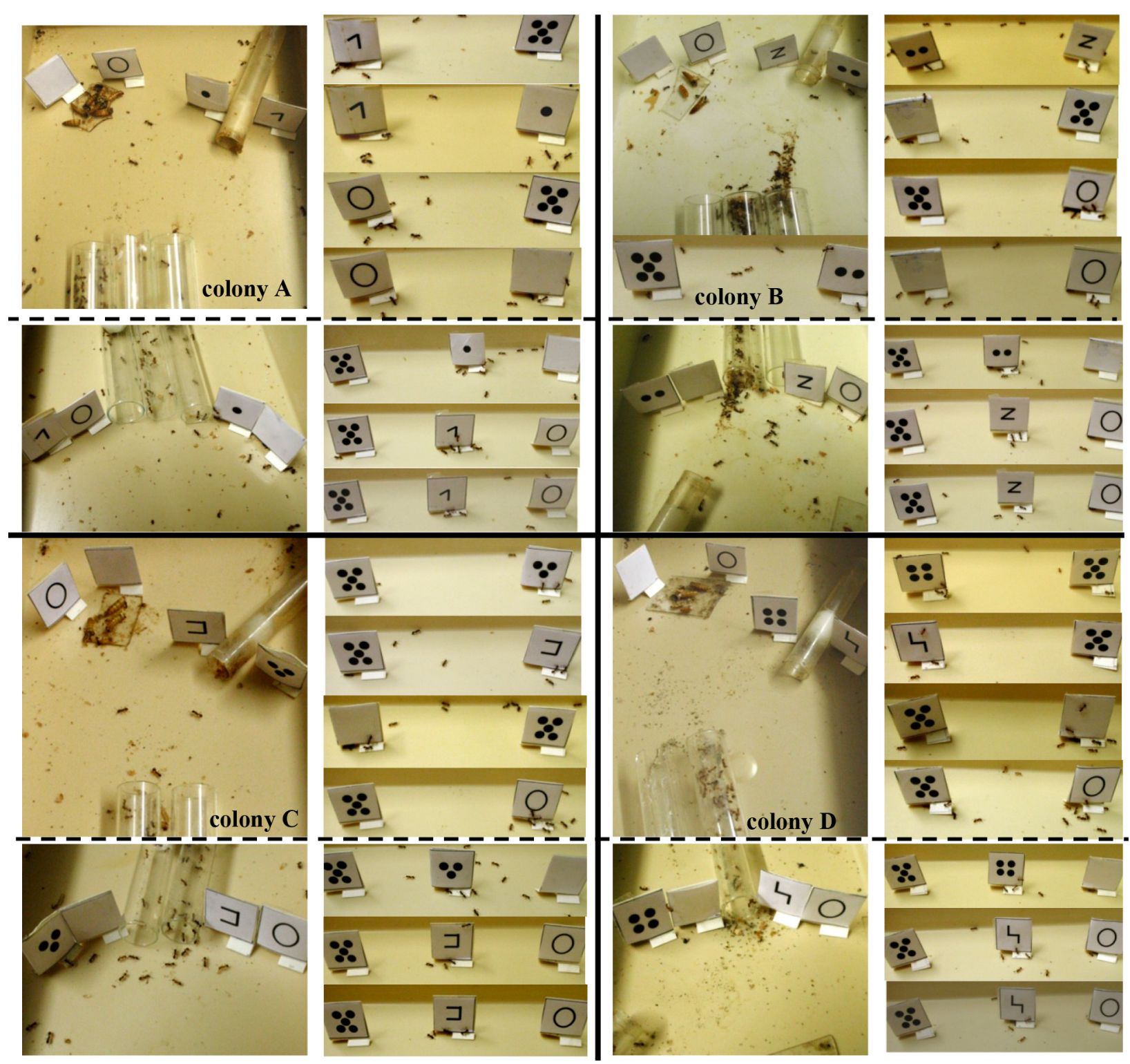

Figure 2. Some photos of the experiments performed on four ant colonies (A, B, C, D) for knowing if the ants could associate the zero with a symbol and use this symbol for making an addition.

The ants were trained to a number of black circles and its corresponding symbol set near the sugar water tube, as well as to a blank paper (= zero circle) and its corresponding symbol set near the meat (for each colony, left photo above the dotted line). A stand bearing 5 circles was located far from any reward. The ants were then tested in front of these cues (for each colony, right photos above the dotted line). After that, they were trained to make a suggested addition: a number of black circles +0 circle were set side by side on one side of the nest entrance, and the symbol of the number + the symbol of zero were set side by side on the other side of the nest entrance (for each colony, left photo below the dotted line). They were then tested for examining if they could make the additions using the numbers as well as the symbols (for each colony, right photos below the dotted line). The ants acquired the proposed symbolisms and made the presented additions. Details of methods and results are given in Figure 1, in Table 1 and in the text.

\section{Results}

Numerical results are presented in Table 1 and photos of the experiments are shown in Figure 2. The results detailed below concerned successively the additions $1+0,2+0,3+0$ and $4+0$, and each time, successively the ants' acquisition of the symbolism corresponding to the number of circles and to the zero, then their use of this acquisition for making the suggested operation. 


\subsection{Learning and use of symbol for zero for making the addition $1+0$}

During their first training session, meanly 16.5 ants of colony A were at any time moving or staying in the vicinity of the six presented cues. They could thus sufficiently see and memorize them.

Facing 1 black circle and 5 ones, the tested ants approached essentially the 1 circle: 45 of their approaches were for the 1 circle while 12 ones were for the 5 circles. These two scores statistically differed $(P=0.031)$. In front of the symbol for 1 and 5 black circles, the tested ants went mostly to the symbol: they did so 52 times while they went 16 times to the 5 circles, two scores also statistically different $(\mathrm{P}=0.031)$. Tested against the symbol for 1 and 1 black circle, the ants visited nearly equally the two cues: 28 visits concerned the symbol and 25 ones the 1 circle, these two scores statistically not differing $(\mathrm{P}=0.626)$. Consequently, since the ants of colonies A identically reacted to the symbol 1 and to the 1 circle, they duly associated to these two elements.

In front of a blank paper (= no circle) and 5 black circles, the ants approached essentially the blank paper: 46 of their approaches were for this cue while 8 ones were for the 5 circles $(P=0.031)$. Tested against the symbol for zero and 5 black circles, the ants also approached essentially the symbol for zero: 47 of their approaches concerned this cue while 13 ones concerned the 5 circles $(P=0.031)$. Faced with the symbol for zero and a blank paper $(=0$, no circle), the ants reacted similarly to the two cues. Indeed, 25 of their reactions were for the symbol and 28 ones for the blank paper ( $=0$ circle) (NS). The ants of colony A, even if having already learned to associate the symbol for 1 with 1 circle, also associated the symbol for zero to the absence of circle, since they reacted in the same way to these two elements.

During their second training session, the ants were meanly 13.1 to forage or to rest near the four new cues presented at their nest entrance. They thus saw them, could memorize them and potentially add up them.

In the presence of 5 black circles, 1 black circle and 0 black circle (= a blank paper), the ants approached mostly the 1 circle: 38 approaches were counted for this cue while 19 ones were counted for the 0 circle and 3 ones for the 5 circles. The ants' response to the 1 circle statistically differed from that to the 5 circles $(P=0.031)$ and from that to the 0 circle $(\mathrm{P}=0.031)$. Their responses to the 5 and the 0 circles differed but were at the limit of significance $(\mathrm{P}=$ 0.063). Thus, the ants correctly responded to the 1 circle, i.e. correctly perceived that $1+0$ circle equaled 1 circle. In the presence of 5 black circles, the symbol for 1 and the symbol for zero, the ants visited mostly the symbol for 1: 48 visits occurred for this cue while 11 ones occurred for the symbol for zero and 7 ones for the 5 circles. The ants' response to the symbol for 1 statistically differed from that to 5 circles $(\mathrm{P}=0.031)$ and from that to the symbol for zero $(\mathrm{P}=0.031)$. Their response to the 5 circles and the symbol for zero did not statistically differ $(\mathrm{P}=$ 0.500 ). Thus, the ants correctly responded to the symbol for 1, i.e. duly perceived that the symbol for $1+$ the symbol for zero $=$ the symbol for 1. They even better responded than when tested against the numbers.

\subsection{Learning and use of symbol for zero for making the addition $2+0$}

During their first training session, the ants of colony B were meanly 12.3 to walk or to stay in the vicinity of the six provided cues which they could thus sufficiently see and memorize.

Tested against 2 and 5 black circles, the ants went essentially towards the 2 circles: 37 of their responses were for that cue while 11 ones were for the 5 circles. The difference between these two responses was significant $(\mathrm{P}=$ 0.031). In front of the symbol for 2 and 5 circles, the ants approached mostly the symbol: they responded 47 times to that cue and 15 times to the 5 circles. The difference between these two scores was significant $(P=0.031)$. In the presence of 2 black circles and the symbol for 2 , the ants similarly reacted to the two cues: 30 reactions were for the 2 circles and 32 ones for the symbol $(\mathrm{P}=0.750)$. Since they reacted similarly to these two cues, the ants duly associated the quantity 2 with the symbol for 2 .

In front of a blank paper (representing zero circle) and 5 black circles, the ants sighted (40) near the blank paper were more numerous than those (14) sighted near the 5 circles. These two scores statistically differed $(\mathrm{P}=0.031)$. In front of the symbol for zero and 5 black circles, the ants sighted near the symbol were largely more numerous (61) than those sighted near the 5 circles (10). These two scores statistically differed $(P=0.031)$. Faced with the symbol for zero and 0 circle (a blank paper), the ants similarly reacted to the two cues: there were 30 reactions for each cue (NS). Having identically reacted to these two elements, the ants thus duly associated the absence of circle with a symbol. Could they use such a symbolism for making the addition $2+0$ ?

During their second training session, meanly 16.1 ants of colony B were walking or staying at any time near the four cues situated near their nest entrance. They could thus see, memorize and potentially add up them.

Tested in front of 5, 2 and 0 black circles, the ants visited essentially the stand bearing 2 circles: 31 visits were for that cue while 6 ones were for the 5 circles and 10 for the 0 circle. The ants' response to the 2 circles statistically differed from those to the 5 and the 0 circles $(\mathrm{P}=0.031)$. The ants' response to the 5 and the 0 circles did not 
statistically differ $(\mathrm{P}=0.219)$. Thus, the ants duly perceived that $2+0$ circles equaled 2 circles. Facing 5 circles, the symbol for 2 and that for zero, the ants responded essentially to the symbol for 2 . Indeed, 38 ants' responses were for that cue while 4 were for the 5 circles, and 7 for the symbol corresponding to zero. The ants' response to the symbol for 2 statistically differed from those to the 5 circles and to the symbol for zero $(\mathrm{P}=0.031)$. Their responses to the 5 circles and to the symbol for zero did not differ $(\mathrm{P}=0.188)$. Thus, the ants perceived the cues 'symbol $2+$ symbol 0 ' as equaling 'symbol 2', or in other words, they summed the symbols 2 and 0 and correctly responded to the symbol 2.

Table 1. Responses of ants trained to associate amounts to symbols, then to add these amounts or their symbols

\begin{tabular}{|c|c|c|c|c|c|c|c|c|c|c|}
\hline \multirow[t]{2}{*}{$\begin{array}{l}\text { Colony, testing session } \\
\text { cues }\end{array}$} & \multicolumn{3}{|c|}{$\begin{array}{l}\mathrm{N}^{\circ} \text { (and \%) of ants } \\
\text { sighted near the cues }\end{array}$} & \multicolumn{4}{|c|}{$\begin{array}{c}\mathrm{N}^{\circ} \text { of ants chronologically } \\
\text { summed by four }\end{array}$} & \multicolumn{3}{|c|}{ Wilcoxon test } \\
\hline & & & & & & & & $\mathrm{N}$ & $\mathrm{T}$ & $\mathrm{P}$ \\
\hline \multicolumn{11}{|l|}{ A, testing I } \\
\hline 1 circle $\quad$ s 5 circles & $45(78.9 \%)$ & $v s$ & $12(21.1 \%)$ & $11,11,9,5,9$ & $v s$ & & $0,0,4,2,6$ & 5 & 15 & 0.031 \\
\hline symbol 1 vs 5 circles & $52(76.5 \%)$ & $v s$ & $16(23.5 \%)$ & $9,11,10,9,13$ & vs & & $1,4,2,2,7$ & 5 & 15 & 0.031 \\
\hline symbol 1 vs 1 circle & $28(52.8 \%)$ & $v s$ & $25(47.2 \%)$ & $7,5,6,5,5$ & vs & & $6,7,4,5,3$ & 7 & 7 & 0.626 \\
\hline 0 circle vs 5 circles & $46(85.2 \%)$ & $v s$ & $8(14.8 \%)$ & $11,9,7,8,11$ & vs & & $1,1,1,2,3$ & 5 & 15 & 0.031 \\
\hline symbol 0 vs 5 circles & $47(78.3 \%)$ & vs & $13(21.7 \%)$ & $11,12,89,7,8$ & vs & & $3,4,2,0,4$ & 5 & 15 & 0.031 \\
\hline $\begin{array}{l}\text { symbol } 0 \text { vs } 0 \text { circle } \\
\text { testing II }\end{array}$ & $25(47.2 \%)$ & vs & $28(52.8 \%)$ & $6,5,4,4,6$ & vs & & $6,6,4,6,6$ & 2 & - & NS \\
\hline $\begin{array}{lllll}5 & \text { vs } & 1 & \text { vs } & 0 \text { circles }\end{array}$ & $3(5.0 \%)$ & $v s \quad 38(63.3 \%)$ & vs $19(31.7 \%)$ & $\begin{array}{ll}0,0,0,0,3 & v s \\
0,0,0,0,3 & \end{array}$ & $\begin{array}{c}5,5,8,10,10 \\
v_{S}\end{array}$ & $v s$ & $\begin{array}{l}0,3,4,7,5 \\
0,3,4,7,5\end{array}$ & $\begin{array}{l}5 \\
4\end{array}$ & $\begin{array}{l}15 \\
10\end{array}$ & $\begin{array}{l}0.031 \\
0.063\end{array}$ \\
\hline 5 circles $v s$ sy 2 vs sy 0 & $7(10.6 \%)$ & vs $48(72.7 \%)$ & vs $11(16.7 \%)$ & $\begin{array}{l}1,0,3,1,2 \quad \text { vs } \\
1,0,3,1,2\end{array}$ & $\begin{array}{c}12,15,7,7,7 \\
v s \\
\end{array}$ & & $\begin{array}{l}0,6,2,2,1 \\
0,6,2,2,1 \\
\end{array}$ & $\begin{array}{l}4 \\
5 \\
\end{array}$ & $\begin{array}{l}10 \\
7.5 \\
\end{array}$ & $\begin{array}{l}0.063 \\
0.500 \\
\end{array}$ \\
\hline \multicolumn{11}{|l|}{ B, testing I } \\
\hline 2 circles vs 5 circles & $37(77.1 \%$ & vs & $11(22.9 \%)$ & $7,7,6,8,9$ & $v s$ & & $0,0,1,4,6$ & 5 & 15 & 0.031 \\
\hline symbol 2 vs 5 circles & $47(75.8 \%$ & $v s$ & $15(24.2 \%)$ & $9,7,9,10,12$ & $v s$ & & $1,3,4,5,2$ & 5 & 15 & 0.031 \\
\hline symbol 2 vs 2 circles & $32(51.6 \%)$ & $v s$ & $30(48.4 \%)$ & $6,8,5,5,8$ & $v s$ & & $5,6,7,5,7$ & 4 & 6.5 & 0.750 \\
\hline 0 circle vs 5 circles & $40(74.1 \%)$ & $v s$ & $14(25.4 \%)$ & $10,7,10,5,8$ & $v s$ & & $1,4,5,0,4$ & 5 & 15 & 0.031 \\
\hline symbol 0 vs 5 circles & $61(85.9 \%)$ & $v s$ & $10(14.1 \%)$ & $11,12,16,13,9$ & $v s$ & & $3,0,2,2,3$ & 5 & 15 & 0.031 \\
\hline $\begin{array}{l}\text { symbol } 0 \text { vs } 0 \text { circle } \\
\text { testing II }\end{array}$ & $30(50.0 \%)$ & $v s$ & $30(50.0 \%)$ & $5,5,6,6,8$ & $v s$ & & $5,5,6,8,6$ & 0 & - & NS \\
\hline 5 vs 2 vs 0 circles & $6(12.8 \%)$ & $v s 31(66.0 \%)$ & vs $10(21.3 \%)$ & $\begin{array}{l}1,3,0,1,1 \quad v s \\
1,3,0,1,1\end{array}$ & $\begin{array}{c}6,6,7,7,5 \\
v s\end{array}$ & $v s$ & $\begin{array}{l}0,2,3,3,2 \\
0,2,3,3,2\end{array}$ & $\begin{array}{l}5 \\
5\end{array}$ & $\begin{array}{l}15 \\
11\end{array}$ & $\begin{array}{l}0.031 \\
0.219\end{array}$ \\
\hline 5 circles vs sy 2 vs sy0 & $4(8.2 \%)$ & vs $38(77.6 \%)$ & ) vs $7(14.3 \%)$ & $\begin{array}{l}0,1,0,0,3 \quad v s \\
0,1,0,0,3\end{array}$ & $\begin{array}{c}10,7,8,6,7 \\
v s\end{array}$ & vs & $\begin{array}{l}2,1,1,1,2 \\
2,1,1,1,2\end{array}$ & $\begin{array}{l}5 \\
4 \\
\end{array}$ & $\begin{array}{c}15 \\
8\end{array}$ & $\begin{array}{l}0.031 \\
0.188\end{array}$ \\
\hline \multicolumn{11}{|l|}{ C, testing I } \\
\hline 3 circles vs 5 circles & $57(82.6 \%)$ & vs & $12(17.4 \%)$ & $9,10,13,14,11$ & vs & & $0,2,6,3,1$ & 5 & 15 & 0.031 \\
\hline symbol 3 vs 5 circles & $66(84.6 \%)$ & $v s$ & $12(15.4 \%)$ & $16,15,11,11,13$ & vs & & $2,5,3,0,2$ & 5 & 15 & 0.031 \\
\hline symbol 3 vs 3 circles & $35(51.5 \%)$ & $v s$ & $33(48.5 \%)$ & $7,6,9,7,6$ & vs & & $5,7,9,6,6$ & 3 & 4.5 & 0.626 \\
\hline 0 circle vs 5 circles & $52(82.7 \%)$ & $v s$ & $8(13.3 \%)$ & $9,10,11,12,10$ & vs & & $0,1,4,3,0$ & 5 & 15 & 0.031 \\
\hline symbol 0 vs 5 circles & $41(85.4 \%)$ & $v s$ & $7(14.6 \%)$ & $4,6,8,13,10$ & vs & & $0,1,0,4,2$ & 5 & 15 & 0.031 \\
\hline $\begin{array}{l}\text { symbol } 0 \text { vs } 0 \text { circle } \\
\text { testing II }\end{array}$ & $33(50.0 \%)$ & $v s$ & $33(50.0 \%)$ & $7,65,7,6,7$ & $v s$ & & $5,5,8,6,9$ & 4 & 5 & 0.563 \\
\hline 5 vs 3 vs 0 circles & $9(16.1 \%)$ & vs $38(67.9 \%)$ & vs $9(16.1 \%)$ & $\begin{array}{l}9,2,2,4,1 \quad v s \\
9,2,2,4,1\end{array}$ & $\begin{array}{c}9,9,6,7,7 \\
v s\end{array}$ & $v s$ & $\begin{array}{l}0,4,1,0,4 \\
0,4,1,0,4\end{array}$ & $\begin{array}{l}5 \\
4\end{array}$ & $\begin{array}{c}15 \\
5\end{array}$ & $\begin{array}{l}0.031 \\
0.563\end{array}$ \\
\hline 5 circles $v$ s sy 3 vs sy 0 & $7(13.7 \%)$ & vs $36(70.6 \%)$ & vs $8(15.7 \%)$ & $\begin{array}{l}3,1,1,1,1 \quad \text { vs } \\
3,1,1,1,1\end{array}$ & $\begin{array}{c}9,7,6,7,7 \\
v s \\
\end{array}$ & $v s$ & $\begin{array}{l}2,3,1,2,0 \\
2,3,1,2,0 \\
\end{array}$ & $\begin{array}{l}5 \\
4 \\
\end{array}$ & $\begin{array}{c}15 \\
6 \\
\end{array}$ & $\begin{array}{l}0.031 \\
0.438\end{array}$ \\
\hline \multicolumn{11}{|l|}{ D, testing I } \\
\hline 4 circles vs 5 circles & $46(78.0 \%)$ & vs & $13(22.8 \%)$ & $8,6,6,9,15$ & vs & & $2,1,0,4,6$ & 5 & 15 & 0.031 \\
\hline symbol 4 vs 5 circles & $49(84.5 \%$ & vs & $9(15.5 \%)$ & $9,7,12,19,11$ & vs & & $0,0,4,1,4$ & 5 & 15 & 0.031 \\
\hline symbol 4 vs 4 circles & $45(51.1 \%)$ & vs & $43(48.9 \%)$ & $6,7,9,10,13$ & vs & & $6,8,7,8,14$ & 4 & 7 & 0.626 \\
\hline 0 circle $\quad$ ss 5 circles & $50(80.6 \%$ & $v s$ & $12(19.4 \%)$ & $12,6,9,10,13$ & vs & & $3,2,2,2,3$ & 5 & 15 & 0.031 \\
\hline symbol 0 vs 5 circles & $74(77.9 \%)$ & $v s$ & $21(22.1 \%)$ & $8,10,16,20,20$ & $v s$ & & $0,2,8,5,6$ & 5 & 15 & 0.031 \\
\hline $\begin{array}{l}\text { symbol } 0 \text { vs } 0 \text { circle } \\
\text { testing II }\end{array}$ & $42(48.8 \%)$ & vs & $44(51.2 \%)$ & $7,10,9,9,7$ & vs & & $7,10,9,9,9$ & 1 & - & NS \\
\hline 5 vs 4 vs 0 circles & $7(13.2 \%)$ & vs $32(60.4)$ vs & $14(26.4 \%)$ & $\begin{array}{l}0,1,4,0,2 \quad v s \\
0,1,4,0,2\end{array}$ & $\begin{array}{c}6,5,8,7,6 \\
\text { vs }\end{array}$ & $v s$ & $\begin{array}{l}1,2,4,4,3 \\
1,2,4,4,3\end{array}$ & $\begin{array}{l}5 \\
4\end{array}$ & $\begin{array}{l}15 \\
10\end{array}$ & $\begin{array}{l}0.031 \\
0.063\end{array}$ \\
\hline 5 circles $v s$ sy 4 vs sy 0 & $6(10.3 \%)$ & $v s 43(71.4 \%)$ & vs $9(15.5 \%)$ & $\begin{array}{l}0,0,1,1, \text { vs } \\
0,0,1,1,4\end{array}$ & $\begin{array}{c}9,8,6,10,10 \\
\text { vs }\end{array}$ & & $\begin{array}{l}1,1,0,3,4 \\
1,1,0,3,4 \\
\end{array}$ & $\begin{array}{l}5 \\
4 \\
\end{array}$ & $\begin{array}{c}15 \\
8\end{array}$ & $\begin{array}{l}0.031 \\
0.188 \\
\end{array}$ \\
\hline
\end{tabular}

Details are given in the text and photos are shown in Figure 3; sy = symbol. The ants could associate the presented symbols with their corresponding amounts, and could make the suggested additions using the numerosities as well as the symbols. 


\subsection{Learning and use of symbol for zero for making the addition $3+0$}

During their first training session, the ants of colony $\mathrm{C}$ were numerous enough in the vicinity of all the provided cues for seeing and memorizing them: they were indeed meanly 13.8 there at any time.

Faced with 5 and 3 black circles, the tested ants approached essentially the 3 circles: 57 approaches were for that cue while 12 ones were for the 5 circles, the difference being significant $(P=0.031)$. Faced with 5 circles and the symbol for 3 , the ants approached essentially the symbol: 66 approaches were for that cue while 12 ones were for the 5 circles, the difference being also significant $(\mathrm{P}=0.031)$. Against the symbol for 3 and 3 black circles, the ants nearly equally visited the two cues: 35 visits were for the symbol and 33 ones for the 3 circles $(\mathrm{P}=0.626)$. Consequently, the ants duly associated the amount 3 with the symbol for 3 since they reacted similarly to these two cues.

In front of a blank paper ( 0 circle $)$ and 5 black circles, the tested ants went mostly to the blank paper: 52 of their reactions were for this cue while 8 ones were for the 5 circles. These two levels of reaction statistically differed (P $=0.031)$. In front of the symbol for zero and 5 black circles, the ants went mostly to the symbol: they did so 41 times while they went 7 times to the 5 black circles. These two scores statistically differed $(P=0.031)$. In the presence of a blank paper and the symbol for zero, the tested ants reacted equally to the two cues: they presented 33 reactions to each of the two presented cues, with no statistical difference between these two levels of reaction $(\mathrm{P}=$ 0.563). Consequently, since they exhibited identical reactions to the zero ( 0 circle) and the symbol for zero, the ants of colony $\mathrm{C}$ duly associated these two cues.

During their second training session (to 3 and zero black circles as well as to the symbol for 3 and that for zero, set at the nest entrance), the ants of colony $\mathrm{C}$ were meanly 17.6 to move or to stay at any time in the vicinity of these four cues, being thus able to see, memorize and potentially add them up.

In front of 5, 3, and 0 black circles, the tested ants visited essentially the 3 circles: 38 of their visits were for that cue while 9 were for the 5 circles and 9 for the blank paper. The numbers of ants sighted near the 3 black circles statistically differed from the numbers sighted near the 5 as well as near the zero circles $(\mathrm{P}=0.031)$. The numbers of ants sighted near the 5 circles and those sighted near the zero circle did not statistically differ $(\mathrm{P}=0.563)$. Thus, the ants correctly perceived that 3 circles +0 circle equaled 3 circles. In front of 5 circles, the symbol for 3 and that for zero, the ants essentially approached the symbol for $3: 36$ approaches were for that cue while 7 were for the 5 circles and 8 for the symbol for zero. The numbers of ants counted near the symbol for 3 statistically differed from those counted near the 5 circles $(\mathrm{P}=0.031)$ and from those counted near the symbol for $1(\mathrm{P}=0.031)$. The numbers of ants counted near the 5 circles did not statistically differ from those counted near the symbol for zero $(\mathrm{P}=0.438)$. Thus, the ants correctly responded that the symbol for $3+$ that for zero equaled the symbol for 3 . The ants used thus the learned symbols for making the suggested addition $3+0=3$.

\subsection{Learning and use of symbol for zero for making the addition $4+0$}

During their first training session, the ants of colony D were meanly 9.3 to walk or to stay all round the six provided cues, which they could thus see and memorize.

Tested in the presence of 5 and 4 black circles, the ants mostly went to the 4 circles: 46 of their reactions were for that cue while 13 were for the 5 circles, the difference being significant $(P=0.031)$. In the presence of the symbol for 4 and 5 black circles, the ants also mostly went to the symbol: 49 of their reactions were for that cue while 9 were for the 5 circles, the difference being also significant $(\mathrm{P}=0.031)$. Against the symbol for 4 and 4 black circles, the ants approached nearly equally to the two cues: 45 of their approaches were to the symbol and 43 ones were to the 4 circles $(P=0.626)$. Since they responded similarly to the amount 4 and the symbol for 4 , the ants duly associated these two cues.

Tested in front of a blank paper ( 0 circle) and 5 black circles, the ants preferentially approached the blank paper: 50 of their approaches concerned that cue while 12 ones concerned the 5 circles, these two scores statistically differing $(\mathrm{P}=0.031)$. In front of the symbol for zero and 5 black circles, the ants also preferentially approached the symbol: 74 of their approaches were to that cue while 21 ones were to the 5 circles $(P=0.031)$. Facing the symbol for zero and a blank paper ( 0 circle), the ants reacted nearly equally to the two cues: 42 of their reactions were for the symbol and 44 ones were for the blank paper (NS). Thus, since they responded similarly to the symbol for zero and to 0 circle (a blank paper), the ants duly associated these two cues.

During their second training session, the ants of colony D were meanly 13.0 to walk or to stay near the four presented cues which they could thus see, memorize and potentially add up.

Against 5, 4, and 0 circles, the ants mostly responded to the 4 circles: 32 of their responses were to that cue while 7 ones were to the 5 circles and 14 ones to the blank paper. The ants' responses to the 4 circles statistically differed from those to the 5 circles and from those to the blank paper (each time: $\mathrm{P}=0.031$ ), while the ants' responses to the 
5 circles and those to the blank paper differed at the limit of significance $(\mathrm{P}=0.063)$. Thus, the ants duly responded that $4+0$ circles (set at their nest entrance) equaled 4 circles. Against 5 circles, the symbol for 4 and that for zero, the ants visited essentially the symbol for 4,43 of their visits being for that cue while 6 ones were for the 5 circles and 9 ones for the symbol for zero. The ants' responses to the symbol for 4 statistically differed from those to the 5 circles as well as from those to the symbol for zero (each time: $\mathrm{P}=0.031$ ). The ants' responses to the 5 circles and those to the symbol for zero did not statistically differ $(\mathrm{P}=0.188)$. Thus, the ants duly responded that the symbol for $4+$ the symbol for zero (set near their nest entrance) equaled the symbol for 4; they made an addition using two symbols, one corresponding to a number and one corresponding to zero.

\section{Discussion}

The present work shows that, through conditioning, ants could acquire numerical symbolism for a number of elements ( 1 to 4 ) and for zero. Based on this acquisition, they succeeded in making the suggested additions $1+0$, $2+0,3+0$ and $4+0$ by using the numbers as well as the symbols. Even if this appeared spectacular, it only resulted for conditioning. Here below, we formulate a few remarks about our experiments, recall similar findings in other animals, and conclude.

The ants appeared to make the best the suggested additions when using the symbols than when using the numbers of elements. Indeed, they presented a score of $63.3 \%, 66.0 \%, 67.9 \%$ and $60.4 \%$ for the additions $1+0,2+0,3+0$ and $4+0$ when using the numbers, and a score of $72.7 \%, 77.6 \%, 70.6 \%$ and $74.1 \%$ for the same additions when using the symbols. As for the acquisition of the numerical symbolism, that relative to zero was higher than that relative to the numbers, except for the number 4 . The ants presented a score of $76.5 \%, 75.8 \%, 84.6 \%$ and $84.5 \%$ for the acquisition of the symbolism corresponding to $1,2,3$ and 4 , while they presented a score of $78.3 \%, 85.9 \%$, $85.4 \%$ and $77.9 \%$ for the acquisition of the symbol zero. The last score $(77.9 \%)$ was low because the tested ants were very numerous in reacting and the place in front of the symbol for zero was quickly saturated; no more ants could approach it and those counted in front of it were fewer than it could have been. On the whole, it can be stated that the ants' learning and using of symbols were better than their counting and using of number of elements. For ants, learning then using symbols appeared to be easier than counting and using numbers of elements. For humans, the use of symbols helps carrying out many tasks such as writing texts, understanding, summarizing, calculating, communicating, writing music, playing cards, etc. This is probably also the case for many evolved animals as for their respective specific tasks.

While studying the ants' acquisition of multiple numerical symbolisms, a distance effect was observed in the ants' responses since they were trained to the numbers 1 to 4 faced with the number 5 (Cammaerts \& Cammaerts, 2020d). Quite the reverse, while studying the ants' adding up symbols, no distance effect was observed since the ants were trained with numbers 1 to 4 versus zero (Cammaerts \& Cammaerts, 2020e). In the present work, the ants' response was again not affected by a distance effect because, during training, the numbers 1 to 4 were in presence not only of the number 5 but also of a zero (and its symbol): the ants' scores corresponding to the numbers 1,2, 3 and 4 equaled $78.9 \%, 77.1 \%, 82.6 \%$ and $78.0 \%$ respectively.

The ants could thus learn and use a symbol for zero (present work). This ability can be detained only by rather old ants since the notion of zero is not innate in ants (as in other animals, including humans) but is acquired in the course of their first or second year of life (Cammaerts \& Cammaerts, 2020b).

Up to now, using numerical symbolism including the zero for making additions has been found only in rhesus monkeys (Washburn \& Rumbaugh, 1991) and in chimpanzees (Boysen \& Berntson, 1989). However, it is plausible that such ability is detained by other animals not yet investigated as for this topic as it seems to facilitate the accomplishment of tasks. For instance, it may be detained by bees since their numerical cognitive skills appear to be at a somewhat higher level than that of ants: adding and subtracting can be learned to honeybees without they have to see beforehand the result of the operation (Howard et al., 2019a) while ants (M. sabuleti) need to sight two numerosities or their symbols at the same time as well as to smell odors side by side in order to sum them (Cammaerts \& Cammaerts, 2019c; 2020a), perhaps by mentally merging two images sighted simultaneously into one single image.

In conclusion, the workers of the ant $M$. sabuleti can acquire single as well as multiple symbolisms including the zero, and can use symbols for making additions. All this results from operative conditioning and occurs only if the result of the additions is shown to the ants during their training. The ants detain this ability of acquiring numerical symbolisms and of using it at a concrete level, without reaching the level of abstraction. Future research on the subject may reveal that other animals also possess such a knowhow. 


\section{References}

Baker, J.M., Morath, J., Rodzon, K.S, \& Jordan, K.E. (2012). A shared system of representation governing quantity discrimination in canids. Frontiers in Psychology, 3 (387). doi:10.3389/fpsyg.2012.00387

Addessi, E., Crescimbene, L., \& Visalberghi, E. (2008). Food and token quantity discrimination in capuchin monkeys (Cebus apella). Animal Cognition, 11, 275-282. doi:10.1007/s10071-007-0111-6

Agrillo, C., Dadda, M., Serena, G., \& Bisazza, A. (2009). Use of number by fish. PLoS One, 4(3), e4786. doi:10.1371/journal.pone.0004786

Agrillo, C., Miletto Petrazzini, M.E., \& Bisazza, A. (2017). Numerical abilities in fish: A methodological review. Behavioural Processes, 141(Pt2), 161-171. doi:10.1016/j.beproc.2017.02.001

Beran, M.J. (2004). Long-term retention of the differential values of Arabic numerals by chimpanzees (Pan troglodytes). Animal Cognition, 7(2), 86-92. doi:10.1007/s10071-003-0191-x

Beran, M.J. (2008). Monkeys (Macaca mulatta and Cebus apella) track, enumerate, and compare multiple sets of moving items. Journal of Experimental Psychology: Animal Behavior Processes, 34(1), 63-74. doi:10.1037/0097-7403.34.1.63

Beran, M.J., Harris, E.H., Evans, T.A., Klein, E.D., Chan, B., Flemming, T.M., \& Washburn, D.A. (2008). Ordinal judgments of symbolic stimuli by capuchin monkeys (Cebus apella) and rhesus monkeys (Macaca mulatta): The effects of differential and non differential reward. Journal of Comparative Psychology, 122(1): 52-61.doi:10.1037/0735-7036.122.1.52

Biro, D., Matsuzawa, T. (2001). Use of numerical symbols by the chimpanzee (Pan troglodytes): cardinals, ordinals, and the introduction of zero. Animal Cognition, 4 (3-4), 193-199. doi:10.1007/s100710100086

Brannon, E., \& Terrace, S. (2000). Representation of the numerosities 1-9 by rhesus macaques (Macaca mulatta). Journal of Experimental Psychology: Animal Behavior Processes, 26(1), 31-49. doi:10.1037//0097-7403.26.1.31

Brannon, E.M., Wusthoff, C.J., Gallistel, C.R., \& Gibbon, J. (2001). Numerical subtraction in the pigeon: Evidence for a linear subjective number scale. Psychological Science, 12(3), 238-243. doi:10.1111/1467-9280.00342

Boysen, S.T., \& Berntson, G.G. (1989). Numerical competence in a chimpanzee (Pan troglodytes). Journal of Comparative Psychology, 103(1), 23. doi:10.1037/0735-7036.103.1.23

Cammaerts M.-C. \& Cammaerts R. (2019a). Ants are at the first stage of the notion of zero. International Journal of Biology, 11(1): 54-65 doi:10.5539/ijb.v11n1p54

Cammaerts, M.-C., \& Cammaerts, R. (2019b). Ants' capability of adding numbers of identical elements. International Journal of Biology, 11(3), 25-36. doi: 10.5539/ijb.v11n3p25

Cammaerts, M.-C., \& Cammaerts, R. (2019c). Ants fail to add numbers of same elements seen consecutively. International Journal of Biology, 11(3), 37-48. doi:10.5539/ijb.v11n3p37

Cammaerts M.-C., Cammaerts R. (2020a). Ants' capability of adding and subtracting odors. International Journal of Biology, 12(1), 1-13. doi:10.5539/ijb.v12n1p1

Cammaerts M.-C., Cammaerts R. (2020b). Ants acquire the notion of zero through experiences. International Journal of Biology, 12(2), 13-25. doi:10.5539/ijb.v12n2p13

Cammaerts, M.-C., \& Cammaerts, R. (2020c). Ants can associate a symbol with a number of elements through conditioning. International Journal of Biology, 12(3), 1-13. doi:10.5539/ijb.v12n3p1

Cammaerts, M.-C., \& Cammaerts, R. (2020d). Ants can acquire multiple symbolisms. International Journal of Biology, 12(3), 14-22. doi:10.5539/ijb.v12n3p18

Cammaerts, M.-C., \& Cammaerts, R. (2020e). Ants can add up using learned numeric symbols. International Journal of Biology, 12(3), 27-39. doi:10.5539/ijb.v12n3p27

Carazo, P., Fernandez-Perea, R., \& Font, E. (2012). Quantity estimation based on numerical cues in the mealworm beetle (Tenebrio molitor). Frontiers in Psychology, 3(502), 1-7. https;//doi.org./10.3389/fpsyg.2012.00502

Cross, F.R., \& Jackson, R.R. (2017). Representation of different exact numbers of prey by a spider-eating predator. Proceedings of the Royal Society, Interface Focus, 7, 20160035. doi:10.1098/rsfs.2016.0035

Cox, L., \& Montrose, V.T. (2016). Quantity discrimination in domestic rats, Rattus norvegicus. Animals, 6(46), 1-9. doi:10.3390/ani6080046 
Ditz, H.M., \& Nieder, A. (2016). Numerosity representations in crows obey the Weber-Fechner law. Proceedings of the Royal Society, B, 283: 20160083. http:/:dx.doi.org/10.1098/rspb.2016.0083

Flombaum, J.I., Junge, J.A., \& Hauser, M.D. (2005). Rhesus monkeys (Macaca mulatta) spontaneously compute addition operations over large numbers. Cognition, 97(3), 315-325. doi:10.1016/j.cognition.2004.09.004

Garland, A., Low, J., \& Burns, K.C. (2012). Large quantity discrimination by North island robins (Petroica longipes). Animal Cognition, 15, 1129-1140. doi:10.1007/s10071-012-0537-3

Garland, A., \& Low, J. (2014). Addition and subtraction in wild New Zealand robins. Behavioural Processes, 109(part B), 103-110. doi:10.1016/j.beproc.2014.08.022

Howard, S.R., Avarguès-Weber, A., Garcia, J.E., Greentree, A.D. \& Dyer, A.G. (2018). Numerical ordering of zero in honey bees. Science 360(6393), 1124-1126. doi:10.1126/science.aar4975

Howard, S.R., Avarguès-Weber, A., Garcia, J.E., Greentree, A.D. \& Dyer, A.G. (2019a). Numerical cognition in honeybees enables addition and subtraction. Science Advances, 5(2): eaav0961. http://doi: 10.1126/sciadv.aav0961

Howard, S.R., Avarguès-Weber, A., Garcia, J.E., Greentree, A.D. \& Dyer, A.G. (2019b). Symbolic representation of numerosity by honeybees (Apis mellifera): Matching characters to small quantities. Proceedings of the Royal Society B, 286: 20190238. doi:10.1098/rspb.2019.0238

Howard, S.R., Avarguès-Weber, A., Garcia, J.E., Greentree, A.D. \& Dyer, A.G. (2019c). Achieving arithmetic learning in honeybees and examining how individuals learn. Communicative \& Integrative Biology, 12(1), 166-170. https:/:doi.org/10.1080/19420889.2019.1678452

Hauser, M.D., MacNeilage, P., \& Ware, M. (1996). Numerical representations in primates. Proceedings of the National Academy of Sciences, USA, Psychology, 93, 1514-1517. doi:10.1073/pnas.93.4.1514

Hauser M.D., Carey, C. \& Hauser, B. (2000). Spontaneous number representation in semi-free-ranging rhesus monkeys. Proceedings of the Royal Society of London B, 267: 829-833. doi:10.1098/rspb.2000.1078.

Hunt, S., Low, J., \& Burns, K.C. (2008). Adaptive numerical competency in a food-hoarding songbird. Proceedings of the Royal Society, B, 275, 2373-2379. doi:10.1098/rspb.2008.0702

Irie, N., Hiraiwa-Hasegawa, M., \& Kutsukake, N. (2019). Unique numerical competence of Asian elephants on the relative numerosity judgment task. Journal of Ethology, 37, 111-115. doi:10.1007/s10164-018-0563-y

Krusche,P., Uller, C., \& Dicke, U. (2010). Quantity discrimination in salamanders. The Journal of Experimental Biology, 213, 1822-1828. doi:10.1242/jeb.039297

Matsuzawa T. (2009). Symbolic representation of number in chimpanzees. Current opinion on Neurobiology, 19: 92-98. doi:10.1016/j.conb.2009.04.007

Murofushi, K. (1997). Numerical matching behavior by a chimpanzee (Pan troglodytes): Subitizing and analogue magnitude estimation. Japanese Psychological Research, 39(32): 140-153. doi:10.1111/1468-5884.00050

Nieder, A. (2016). Representing something out of nothing: The dawning of zero. Trends in Cognitive Sciences. 20 (11), 830-842. doi:10.1016/j.tics.2016.08.008

Olthof, A., Iden, C.M., \& Roberts, W.A. (1997). Judgments of ordinality and summation of number symbols by squirrel monkeys (Saimiri sciureus). Animal Behavior Processes, 23(3): 325-339. Doi.org/10.1037/0097-7403.23.3.325

Pepperberg, I. M. (1988). Comprehension of "absence" by an African Grey parrot: Learning with respect to questions of same/different. Journal of the Experimental Analysis of Behavior, 50(3), 553-564. doi:10.0901/jeab.1988.50-533

Pepperberg, I.M. (1994). Numerical competence in an African grey parrot (Psittacus erithacus). Journal of Comparative Psychology, 108(1), 36-44. doi:10.1037/0735-7036.108.1.36

Pepperberg, I. M. (2006a). Grey parrot (Psittacus erithacus) numerical abilities: Addition and further experiments on a zero-like concept. Journal of Comparative Psychology, 120(1), 1-11. doi:10.1037/0735-7036.120.1.1

Pepperberg, I.M. (2006b) Grey parrot numerical competence: A review. Animal Cognition, 9(4), 377-391. psycnet.apa.org/record/2007-07451-012

Pepperberg, I. M., \& Gordon, J. D. (2005). Number comprehension by a grey parrot (Psittacus erithacus), including a zero-like concept. Journal of Comparative Psychology. 119(2): 197-209. doi:10.1037/0735-7036.119.2.197. 
Pepperberg, I.M. (2012). Further evidence for addition and numerical competence by a Grey parrot (Psittacus erithacus). Animal Cognition, 15(4): 711-717. doi:10.1007/s10071-012-0470-5

Perdue, B.M, Talbot, C.F., Stone, A.M., \& Beran, M.J. (2012). Putting the elephant back in the herd: Elephant relative quantity judgments match those of other species. Animal Cognition, 15, 955-961. doi:10.1007/s10071-012-0521-y

Range, F., Jenikejew, J., Schröder, I., \& Virányi, Z. (2014). Difference in quantity discrimination in dogs and wolves. Frontiers in psychology, 5(1299), 1-10. doi:10.3389/fpsyg.2014.01299

Rodriguez, R.L., Briceno, R.D., Briceno-Aguilar, E., \& Höbel, G. (2015). Nephila clavipes spiders (Araneae: Nephilidae) keep track of captures prey counts: Testing for a sense of numerosity in an orb-weaver. Animal Cognition, 18(1), 307-314. doi:10.1007/s10071-014-0801-9

Rose, G.J. (2018). The numerical abilities of anurans and their neural correlates: Insights from neuroethological studies of acoustic communication. Philosophical Transactions of the Royal Society B: Biological Sciences 373 http://doi.org/10.1098/rstb.2016.0512

Rugani, R., Fontanari, L., Simoni, E., Regolin, L., \& Vallortigara, G. (2009). Arithmetic in newborn chicks. Proceedings of the Royal Society, B, 276, 2451-2460. doi:10.1098/rspb.2009.0044

Rugani, R., Villortigara, G., \& Regolin, L. (2014). From small to large: Numerical discrimination by young domestic chicks (Gallus gallus). Journal of Comparative Psychology, 128(2), 163-171. doi:10.1037/a0034513

Rumbauch, D.M., Savage-Rumbauch, S., \& Hegel, M.T. (1987). Summation in the chimpanzee (Pan troglodytes). Journal of Experimental Psychology: Animal Behavior Processes, 13(2), 107-115. doi:10.1037/0097-7403.13.2.107

Siegel, S., \& Castellan, N.J. (1989). Nonparametric statistics for the behavioural sciences. Singapore, McGraw-Hill Book Company. https://www.amazon.com/Sidney-Siegel...Statistics.../B008WDIR6

Stancher, G., Sovrano, V.A, Potrich, D., \& Vallortigara, G. (2013). Discrimination of small quantities by fish (redtail splitfin, Xenotoca eiseni). Animal Cognition, 16, 307-312. doi:10.1007/s10071-012-0590-y

Stancher, G., Rugani, R., Regolin, L., \& Villortigara, G. (2015). Numerical discrimination by frogs (Bombina orientalis). Animal Cognition, 18, 219-229. doi:10.1007/s10071-014-0791-7

Sulkowski, G.M., \& Hauser, M.D. (2001). Can rhesus monkeys spontaneously subtract? Cognition, 79(3), 239-262. https://doi.org/10.1016/S0010-0277(00)00112-8

Tomonaga, M. (2008). Relative numerosity discrimination by chimpanzees (Pan troglodytes): Evidence for approximate numerical representations. Animal Cognition, 11, 43-57. Doi 10.1007/s10071-007-0089-0

Tornick, J.K., Callahan, E.S., \& Gibson, B.M. (2015). An investigation of quantity discrimination in Clark's nutcrackers (Nucifraga Columbiana). Journal of Comparative Psychology, 129(1), 17-25. http:/:dx.doi.org/10.1037/a0037863

Uller, C., Hauser, M., \& Carey, S. (2001). Spontaneous representation of number in cotton-top tamarins (Saguinus oedipus). Journal of Comparative Psychology, 115(3), 248-257. doi:10.1037//0735-7036.115.3.248

Uller, C., Jaeger, R., Guidry, G., \& Martin, C. (2003). Salamanders (Plethodon cinereus) go for more: Rudiments of number in an amphibian. Animal Cognition, 6, 105-112. doi:10.1007/s10071-003-0167-x

Washburn, D.A., \& Rumbauch, D.M. (1991). Ordinal judgments of numerical symbols by macaques (Macaca mulatta). Psychological Science, 2(3): 190-193. doi:10.1111/j.1467-9280.1991.tb00130.x

Woodruff, G., \& Premack, D. (1981). Primative [sic] mathematical concepts in the chimpanzee: Proportionality and numerosity. Nature, 293 (5833): 568-570. doi:10.1038/293568a0.

Xia, L., Sieman, M., \& Delius J. D. (2000). Matching of numerical symbols with number of responses by pigeons. Animal Cognition. 3: 35-43. doi:10.1007/s100710050048

\section{Copyrights}

Copyright for this article is retained by the author(s), with first publication rights granted to the journal.

This is an open-access article distributed under the terms and conditions of the Creative Commons Attribution license (http://creativecommons.org/licenses/by/4.0/). 